\title{
A fatal case of neurofibromatosis with hemothorax
}

\author{
HongJu Shin* and Gyeong Ae Lee RN \\ Department of Thoracic and Cardiovascular Surgery, Korea University Ansan Hospital, Korea
}

\begin{abstract}
Neurofibromatosis I can cause various symptoms and complications ranging from clinically mild cutaneous pigmentations to malignant nervous system tumors. Although it is known that vascular lesion complications occur in only about 3.6\% of patients, they can be life-threatening. Our Case was a 64 -year-old female patient with a known history of neurofibromatosis type I. The chest X-ray showed massive left pleural effusion. We inserted a chest tube into the patient's pleural space and drained effusion through it. Because there was no active bleeding and the patient's vital sign was stable, we planned to wait for a few days in the intensive care unit before surgery. However, on the next day in the evening, suddenly the patient showed bleeding symptoms and expired. Here we present a fatal case of neurofibromatosis type I with hemothorax.
\end{abstract}

\section{Introduction}

Neurofibromatosis type I is an autosomal dominant disorder that can cause various complications. Especially, vascular abnormalities such as stenosis, occlusions, aneurysms, arteriovenous malformations, and fistula are well recognized but uncommon [1]. Massive fatal hemothorax caused by vascular complications can result in hazardous situations for patients. Therefore, appropriate and timely treatment of hemothorax is very important for early diagnosis and prognosis for patients.

\section{Case report}

A 64-year old woman with known Neruofibromatosis type I had a one-day history of cough, left pleuritic pain, and dizziness, and she had experienced pre-syncope once before her admission to local hospital emergency room. The chest X-ray showed massive left pleural effusion (Figure 1). The initial hemoglobin level was $8.7 \mathrm{~g} / \mathrm{dl}$, quickly deteriorating to $6.4 \mathrm{~g} / \mathrm{dl}$. However, the hospital was not able to carry out

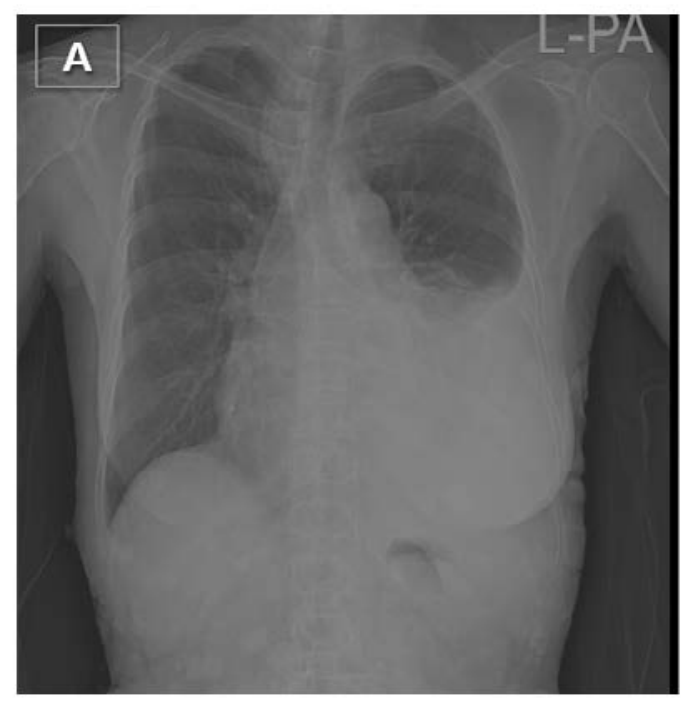

Figure 1. The chest X-ray showed massive left pleural effusion blood transfusion immediately, so the patient was transferred into our hospital for further treatment. When the patient arrived at our hospital, she was completely conscious. The computed tomography (CT) images taken from the local hospital seemed to show no definite active bleeding focus, but we asked to the department of radiology for a formal reading for assurance. On the examination, her initial blood pressure was 90/45 $\mathrm{mmHg}$, heart rate was 90 per min, respiratory rate was 18 per min, and body temperature was $37.6^{\circ} \mathrm{C}$. Initial blood tests showed hemoglobin of $6.5 \mathrm{~g} / \mathrm{dl}$, hematocrit value of $19 \%$, and platelet count of 172,000/ul. Arterial blood gas analysis result was $\mathrm{pH} 7.45, \mathrm{PCO}_{2} 33.9 \mathrm{mmHg}, \mathrm{PO}_{2}$ $68.2 \mathrm{mmHg}$ and BE $-0.49 \mathrm{mmol} / \mathrm{L}$. On physical examination, the patient had numerous subcutaneous nodules all over her entire body. We started blood transfusion and provided coagulants immediately. Then we performed closed thoracotomy on the patient's left side. The amount of chest tube drainage was $1400 \mathrm{ml}$ and it had bloody appearance. Since the patient had no trauma history, it was assumed that her symptom was due to a spontaneous hemothorax. We confirmed the patient's fasting time and arranged an operating room to prepare for emergent surgery to evacuate hematoma. However, the patient no longer had bleeding symptoms, and hemoglobin level increased from $6.5 \mathrm{~g} / \mathrm{dl}$ to $10.6 \mathrm{~g} / \mathrm{dl}$ after two packs of red blood cell transfusion in the emergency room. The next day was the weekend, so we changed our plan to do surgery in the following week. The patient was transferred from the emergency room to the intensive care unit, and we decided to observe her condition over the weekend. Next day, the chest X-ray showed slight overall improvement and her vital sign was stable. The amount of chest tube drainage was $120 \mathrm{cc}$ for eight hours from 06:00 am to 2:00 pm. But at around 08:00 PM, the patient began to express strong left shoulder pain, and suddenly the bloody fluid gushed out of chest tube in large

${ }^{\star}$ Correspondence to: Hong Ju Shin, Department of Thoracic and Cardiovascular Surgery, Korea University Ansan Hospital, 123, Jeokeum-ro, Danwon-gu, Ansan-city, Gyeonggi-do, 425-707, Korea, Tel:+82-31-412-5060, Fax:+82-31414-3249; E-mail: babymedi@naver.com

Key words: hemothorax, neurofibromatosis, neurofibromatosis complication

Received: August 01, 2019; Accepted: August 14, 2019; Published: August 18, 2018 

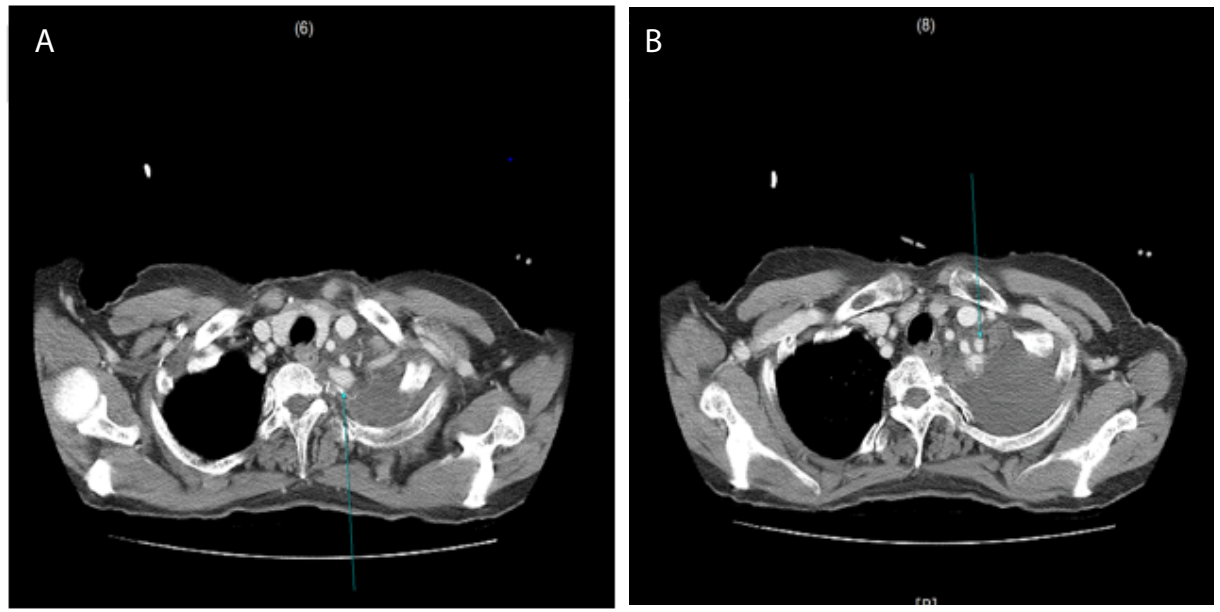

Figure 2. Computed tomography showing aneurysmal dilatation of left internal mammary and subclavian artery

amounts. We clamped the chest tube with a Kelly, hoping to control bleeding that arose from the formation of hematoma in the thoracic cavity. Nonetheless, the patient became rapidly hemodynamically unstable and soon the pulse was not measured; we immediately carried out intubation and chest compression. Although we continued chest compression for more than one hour and a large amount of blood was transfused, the patient expired after all. Two days after her death, we were able to confirm the dilatation of the internal mammary artery and subclavian artery in the formal CT reading (Figure 2A, 2B).

\section{Discussion}

Neurofibromatosis I is an autosomal dominant disorder characterized by abnormal cutaneous pigmentation and numerous skin tumors [2]. Neurofibromatosis I can cause various complications. Of these, vascular lesion complications occur in only $3.6 \%$ of patient; however, they can lead to life-threatening results [2]. In general, criteria for operative or interventional treatment for vascular diseases are the presence of symptoms, rupture, or large aneurysm size [3]. In hemodynamically stable patients, percutaneous endovascular intervention is known to be a favorable and effective diagnostic and therapeutic option. In hemodynamically unstable patients, on the other hand, surgical treatment can be considered [4]. However, surgical treatment is sometimes limited by patients' arterial fragility, and the prognosis is relatively poor compared to other intervention treatments. In recent cases, good results in endovascular intervention therapy of NF1 with arterial rupture have been reported [5-7]. In our case, CT findings after patient's death showed aneurysmal dilatation of left internal mammary and subclavian artery; the reason for the patient's sudden death was suspected to be arterial rupture. In this case, as in the previous reports, an interventional treatment seemed to be a more effective and appropriate treatment option than a surgical approach. However, we did not fully understand the relationship between neurofibromatosis and hemothorax and did not make proper decision for the treatment. Therefore, here we emphasize that in this case, prompt diagnosis and appropriate treatment should be given to neurofibromatosis patients with hemothorax.

ORCID: 0000-0002-3098-7032

\section{Conflicts of interest}

No potential conflicts of interest relevant to this article was reported.

\section{References}

1. Slisatkorn W, Subtaweesin T, Laksanabunsong P, Warnnissorn M (2003) Spontaneous Rupture of the Left subclavian Artery in Neurofibromatosis. Asian Cardiovascular \& thoracic annals 11: 266-268.

2. Brasfield RD, Das Gupta TK (1972) Von Recklinghausen's Disease:A Clinicopathological Study. Ann Surg 175: 86-104. [Crossref]

3. Oderich GS, Sullivan TM, Bower TC, Gloviczki P, Miller DV, et al. (2007) Vascular abnormalities in patients with neurofibromatosis syndrome type I: Clinical spectrum, management, and results. J Vasc Surg 46: 475-484. [Crossref]

4. Teitelbaum GP, Hurvitz RJ, Esrig BC (1998) Hemothorax in type I Neurofibromatosis Ann Thorac Surg 66: 569-571. [Crossref]

5. Miura T, Kawano Y, Chujo M, Miyawaki M, Mori H, et al. (2005) Spontaneous Hemothorax in patients with von Recklinghausen's Disease. Jpn J Thoracic and cardiovascular surg 53: 649-652. [Crossref]

6. Arai K, Sanada J, Kurozumi A, Watanabe T, Matsui O (2007) Spontaneous Hemothorax in Neurofibromatosis Treated With Percutaneous Embolization. Cardiovasc Intervent Radiol 30: 477-479. [Crossref]

7. Dominguez J, Sancho S, Escalante E, Morera JR, Moya JA, et al. (2002) Percutaneous treatment of a ruptured intercostal aneurysm presenting as massive hemothorax in a patient with type I neurofibromatosis. J Thorac Cardiovasc Surg 124: 1230-1232. [Crossref] 